\title{
Commentary: Another look at stage I Norwood outcomes from a different perspective
}

\author{
Andrew J. Lodge, MD
}

\footnotetext{
From the Pediatric and Congenital Heart Center, Division of Cardiovascular and Thoracic Surgery, Department of Surgery, Duke University Medical Center, Durham, NC.

Disclosures: Author has nothing to disclose with regard to commercial support.

Received for publication July 30, 2019; revisions received July 30, 2019; accepted for publication July 31, 2019; available ahead of print Oct 30, 2019.

Address for reprints: Andrew J. Lodge, MD, Duke University Medical Center, Box 3340, Durham, NC 27710

(E-mail: andrew.lodge@duke.edu).

J Thorac Cardiovasc Surg 2020;159:1049-50

$0022-5223 / \$ 36.00$

Copyright (c) 2019 by The American Association for Thoracic Surgery

https://doi.org/10.1016/j.jtcvs.2019.07.145
}

The medical literature is replete with studies describing outcomes of operations for hypoplastic left heart syndrome and its variants. ${ }^{1-5}$ The stage I Norwood procedure has been of particular interest in light of its relatively recent introduction, higher earlier mortality, evolution, technical modifications, and status as a benchmark of performance of a congenital heart program. The vast majority of these reports are from North America and Europe. In contrast, the article by Ismail and colleagues ${ }^{6}$ in this issue of The Journal of Thoracic and Cardiovascular Surgery documents the experience of a program in Saudi Arabia, which is described as a developing country. Specific aspects of care that lead Ismail and colleagues ${ }^{6}$ to characterize the country as such are deficiencies in prenatal diagnosis, problems with timely access to tertiary care facilities, a shortage of intensive care nursery beds, and the limited number of centers that offer the Norwood operation. It is not uncommon for patients with single-ventricle circulations to wait for weeks on a prostaglandin infusion for transfer to a facility where they can receive definitive care. Given the challenges of managing these patients under the best of circumstances, one can speculate that in a setting of limited resources, the challenge could be formidable.

Given this setting, Ismail and colleagues ${ }^{6}$ are to be congratulated not only on the results presented in their article but on the improvements made over time. The primary difference in their patients relative to other contemporary series is their age-almost one month at the time of the Norwood procedure. This difference may be important, as studies have shown that older age at Norwood operation can be a risk factor for poor outcome. ${ }^{3}$ Despite this older age at operation, results at the program of Ismail and colleagues ${ }^{6}$ in the current era are on par with those of centers of excellence in North America and Europe. In addition, hospital length of stay after surgery was also comparable at 22 to 31 days, depending on the group. One of the most unusual aspects of the study is the inclusion of a group of 7 patients who underwent a superior cavopulmonary shunt as the sole source of pulmonary blood flow

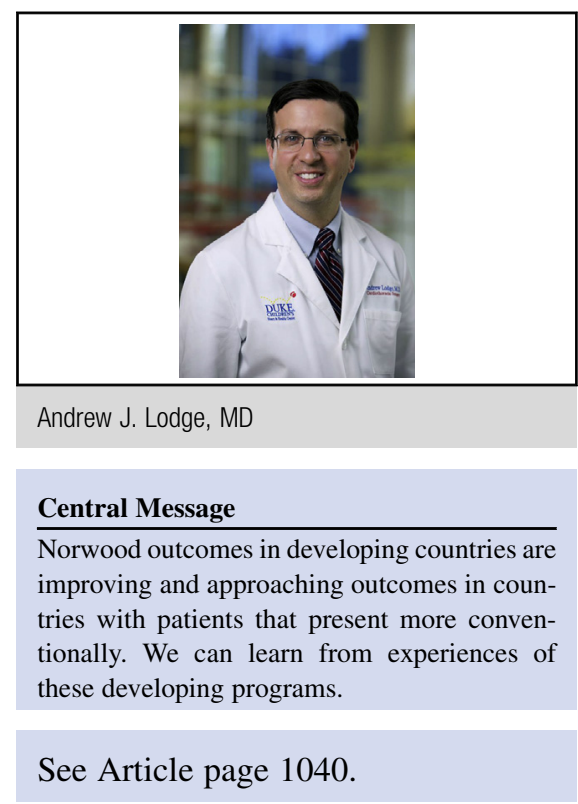

during the Norwood operation (as opposed to a modified Blalock-Taussig or right ventricle-pulmonary artery shunt). Ismail and colleagues ${ }^{6}$ point out that this was a group of older patients - roughly 3 months old —who had evidence of significant pulmonary overcirculation (small for age, oxygen saturation $>95 \%$ ) and a high pulmonary to systemic blood flow ratio and low pulmonary vascular resistance by catheterization. Importantly, despite the fact that patients in this group were an average of 3 to 4 months old, they were only an average weight of $3.6 \mathrm{~kg}$ - significantly smaller than patients at time of the second stage undergoing standard staged palliation. This group had a remarkable operative survival of $100 \%$, but they did require a slightly longer hospital stay. Description of this unusual approach, as well as the specific criteria that were used to select these patients, is a useful addition to the literature.

Despite its strengths, this study also has some important limitations. Perhaps the most notable is that only patients who underwent the Norwood procedure were included in the analysis. It is not clear how many other patients either died while waiting or were considered not to be candidates at the time of presentation because of problems related to late diagnosis or transfer. Although it is stated in the article that late presentation is not a contraindication to the Norwood procedure, it is not clear what inclusion or exclusion criteria were used or what percentage of latepresenting patients will be candidates. Another important 
limitation is that, although operative mortality has improved in the recent eras, according to the transition between states analysis, there was a higher proportion overall of patients who died than those who underwent Fontan operation. It is also not clear how many patients from each group were able to undergo a completion Fontan operation, or whether there were differences between the groups. Of particular interest will be how many of the patients with primary cavopulmonary shunt were able to successfully transition to a Fontan circulation and what the timing is, given their small size at the time of cavopulmonary shunt placement.

Publications like that of Ismail and colleagues ${ }^{6}$ are valuable, because they may help to guide the practice of many of us who work in more developed systems when our patients present in unconventional ways or times. We should look forward to further work from this group detailing the continued evolution of their program and their longer term outcomes with these challenging patients.

\section{References}

1. Ohye RG, Schranz D, D'Udekem Y. Current therapy for hypoplastic left heart syndrome and related single ventricle lesions. Circulation. 2016;134: 1265-79.

2. Wilder TJ, McCrindle BW, Phillips AB, Blackstone EH, Rajeswaran J, Williams WG, et al. Survival and right ventricular performance for matched children after stage-1 Norwood: modified Blalock-Taussig shunt versus rightventricle-to-pulmonary-artery conduit. J Thorac Cardiovasc Surg. 2015;150: $1440-52$.

3. Anderson BR, Ciarleglio AJ, Salavitabar A, Torres A, Bacha EA. Earlier stage 1 palliation is associated with better clinical outcomes and lower costs for neonates with hypoplastic left heart syndrome. J Thorac Cardiovasc Surg. 2015;149: 205-10.e1

4. Tabbutt S, Ghanayem N, Ravishankar C, Sleeper LA, Cooper DS, Frank DU, et al. Risk factors for hospital morbidity and mortality after the Norwood procedure: a report from the Pediatric Heart Network Single Ventricle Reconstruction Trial; Pediatric Heart Network Investigators. J Thorac Cardiovasc Surg. 2012;144:882-95.

5. Ohye RG, Sleeper LA, Mahony L, Newburger JW, Pearson GD, Lu M, et al; Pediatric Heart Network Investigators. Comparison of shunt types in the Norwood procedure for single-ventricle lesions. N Engl J Med. 2010; 362:1980-92.

6. Ismail MF, Elmahrouk AF, Arafat AA, Hamouda TE, Alshaikh BA, Shihata MS, et al. Evolution of the Norwood operation outcomes in patients with late presentation. J Thorac Cardiovasc Surg. 2020;159:1040-8. 